\title{
EFFECT OF CHROMATE ANION ON THE PHOTOCATALYTIC ACTIVITY OF Mg-AI LAYERED DOUBLE HYDROXIDE
}

A. Nehdi ${ }^{1}$, J.Fragoso ${ }^{2}$, N. Frini-Srasra ${ }^{1}$, I. Pavlovic ${ }^{2}$ and L. Sánchez ${ }^{2}$

1'Laboratoire des Matériaux Composites et Minéraux Argileux, Centre National de Recherches en Sciences des Matériaux CNRSM, Technopôle Borj Cedria, BP 73, 8027 Soliman, Tunisie

2Departamento de Química Inorgánica, Instituto Universitario de Nanoquímica IUNAN, Universidad de Córdoba, Campus de Rabanales, E-14071 Córdoba, Spain

\section{INTRODUCTION}

Nowadays, the world large urban areas present problems related to air pollution. The last report of the European Environment Agency [1] estimates around 400.000 premature deaths per year in the European Union due to the quality of the air. The presence of particulate material (PM), ozone, sulphur and nitrogen oxides origins harmful to the human health and the environment. Nitrogen oxides $\left(\mathrm{NO}_{x}\right.$ the sum of nitrogen monoxide, $\mathrm{NO}$, and nitrogen dioxide, $\mathrm{NO}_{2}$ ) are consider as one of the priority air pollutant due to its several adverse and harmful effects. They are responsible for such environmental problems as photochemical smog, tropospheric ozone or acid rain and, related to the human health, they can cause emphysemas, bronchitis, etc. [2].This gases are produced in the city by the burning of fossil fuels. Photocatalytic oxidation of $\mathrm{NO}_{x}$ gases with different materials $\left(\mathrm{TiO}_{2}, \mathrm{ZnO}\right.$, etc.) has proven to be an effective method to reduce the concentration of these compounds. However, in recent year layered double hydroxides have been shown as a promising photocatalysts [3].
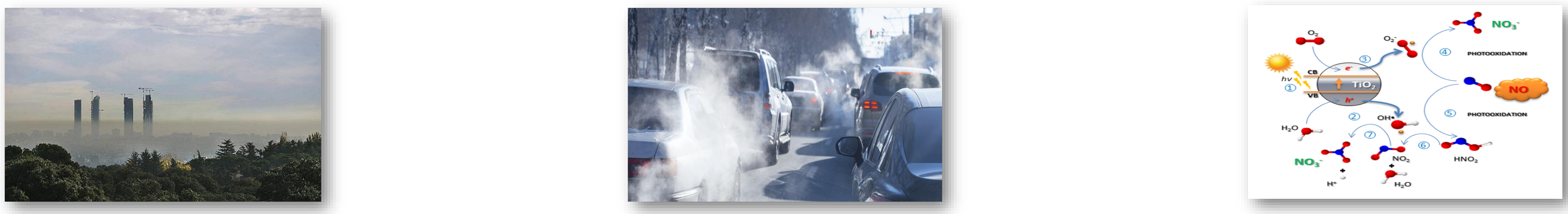

\section{STRUCTURE OF LDH}

\section{SYNTHESIS}

GENERAL FORMULA: $\left[\mathrm{M}_{1-x}^{I I} M_{x}^{I I I}(\mathrm{OH})_{2}\right]\left(A^{n-}\right)_{x / n} \cdot m \mathrm{H}_{2} \mathrm{O}$

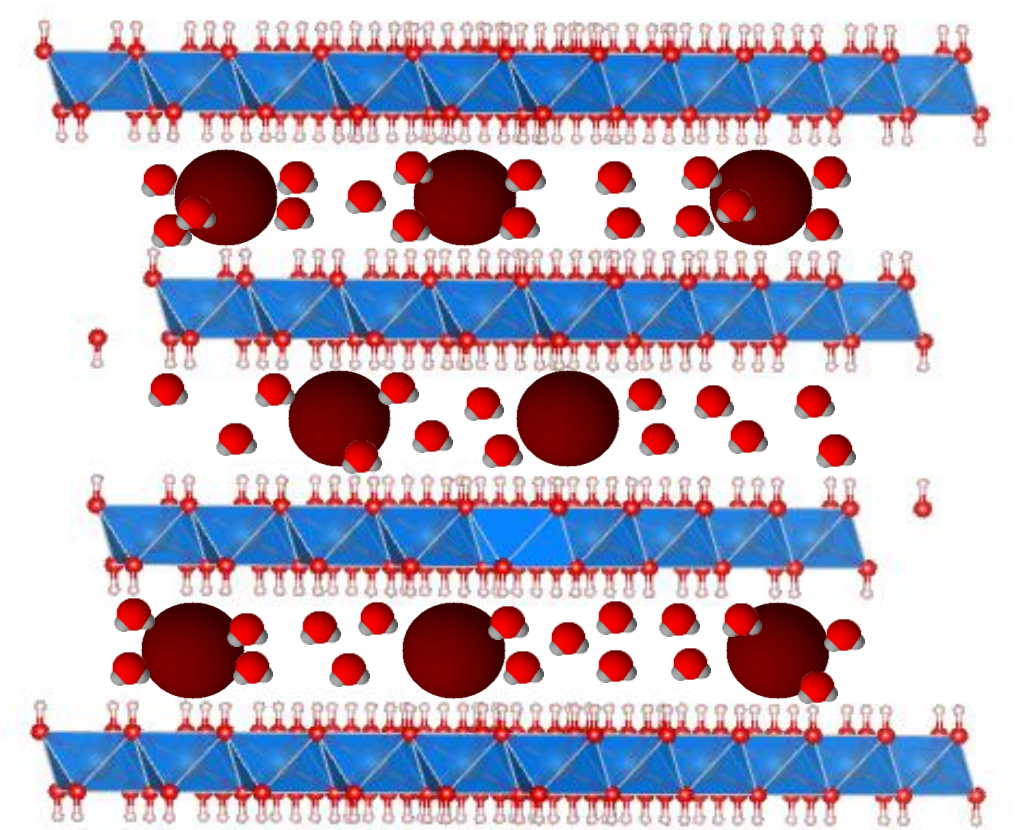

$$
\begin{aligned}
& \text { \& }\left[M_{1-x}^{I I} M_{x}^{I I I}(\mathrm{OH})_{2}\right]^{x+}\left\{\begin{array}{l}
\mathrm{M}^{I I}=\mathrm{Mg}^{2+}, \mathrm{Zn}^{2+}, \mathrm{Ni}^{2+}, \ldots \\
\mathrm{M}^{I I I}=\mathrm{Al}^{3+}, \mathrm{Cr}^{3+}, \mathrm{Fe}^{3+},
\end{array}\right. \\
& A^{n-} \sqrt{\text { Inorganic anions: } \mathrm{Cl}^{-}, \mathrm{CO}_{3}{ }^{2-}, \mathrm{NO}_{3}{ }^{-},} \\
& \text {- } \mathrm{H}_{2} \mathrm{O} \text { Organic acid: adipic, oxalic, succinic, }
\end{aligned}
$$

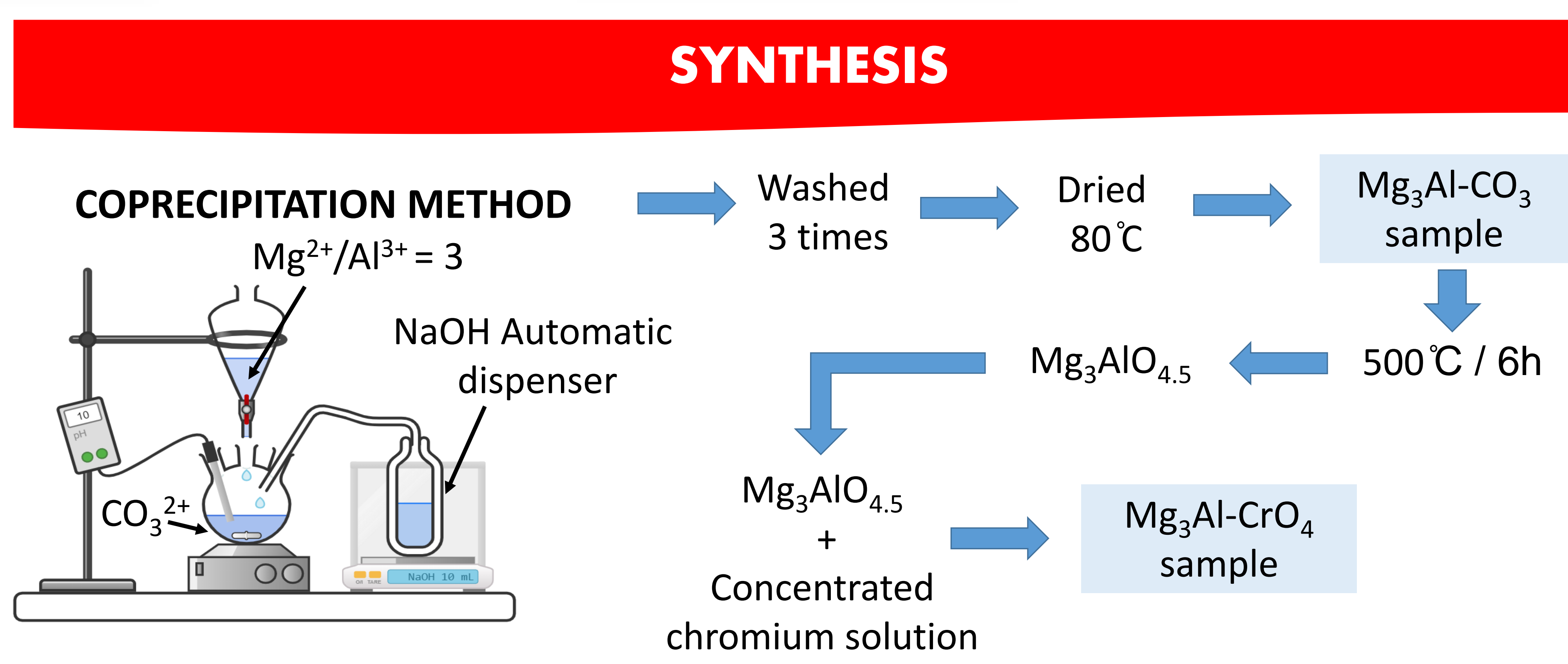

\section{RESULTS}
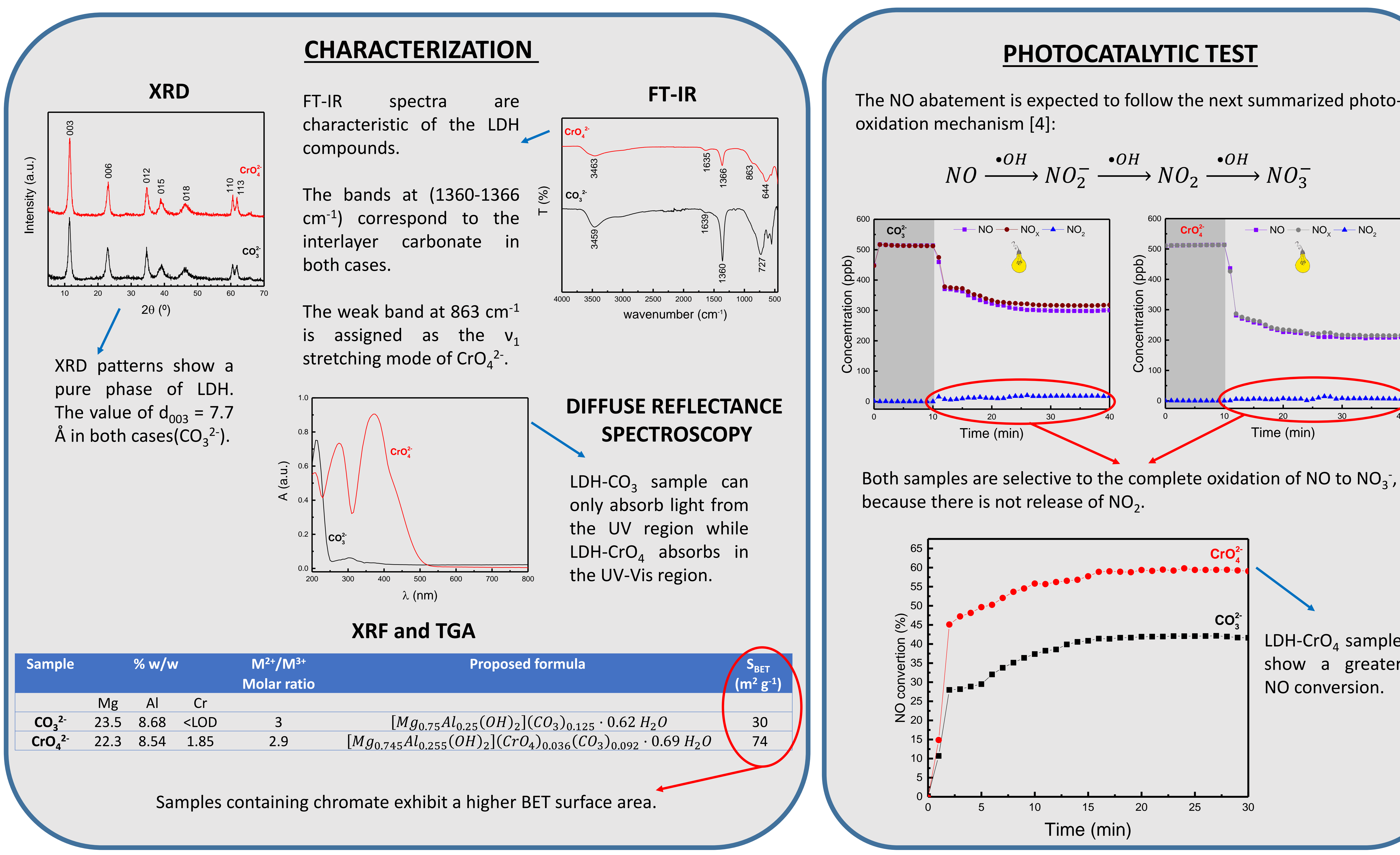

Both samples are selective to the complete oxidation of $\mathrm{NO}$ to $\mathrm{NO}_{3}$ because there is not release of $\mathrm{NO}_{2}$.

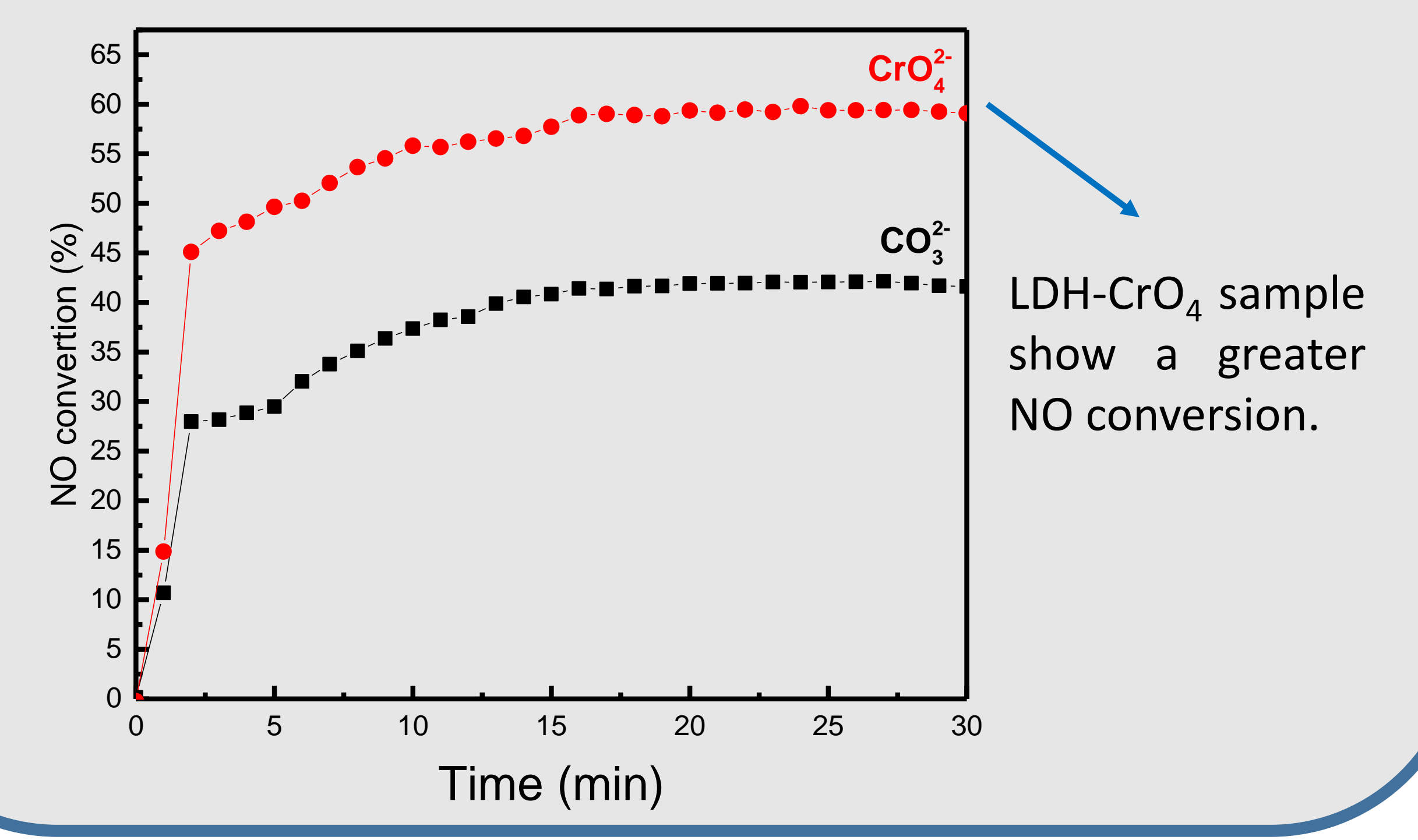

\section{CONCLUSIONS}

A. The presence of chromate on MgAl-CO $\mathrm{CO}_{3} \mathrm{LH}$ enables the UV-Vis light absorption. The chromate sample exhibits a higher specific surface area.

B. Physical and morphological characteristics of the chromate sample facilitate a high NO conversion of $60 \%$.

C. The relevant production of $\mathrm{O}_{2}$ - radicals could be ascribed to the new electronic pathways for the chromate the sample.

\section{REFERENCES}

[1] Air quality in Europe-2019 report. European Environment Agency, Luxembourg, Publications Office of the European Union, 2019

[2] F. Rodriguez-Rivas, A. Pastor, C. Barriga, M. Cruz-Yusta, L. Sánchez, I. Pavlovic, Chem. Eng. J. 346 (2018) 151. 3] A. Pastor, F. Rodriguez-Rivas, G.d. Miguel, M. Cruz-Yusta, F. Martin, I. Pavlovic, L. Sánchez, Chem. Eng. J 387 (2020) 124110

[4] J. Balbuena, M. Cruz-Yusta, L. Sánchez, J. Nanosci. Nanotechnol. 15 (2015) 6373-6385.

\section{REACTIVE OXIGEN SPECIES DETERMINATION}

DMPO SPIN-TRAPPING EPR

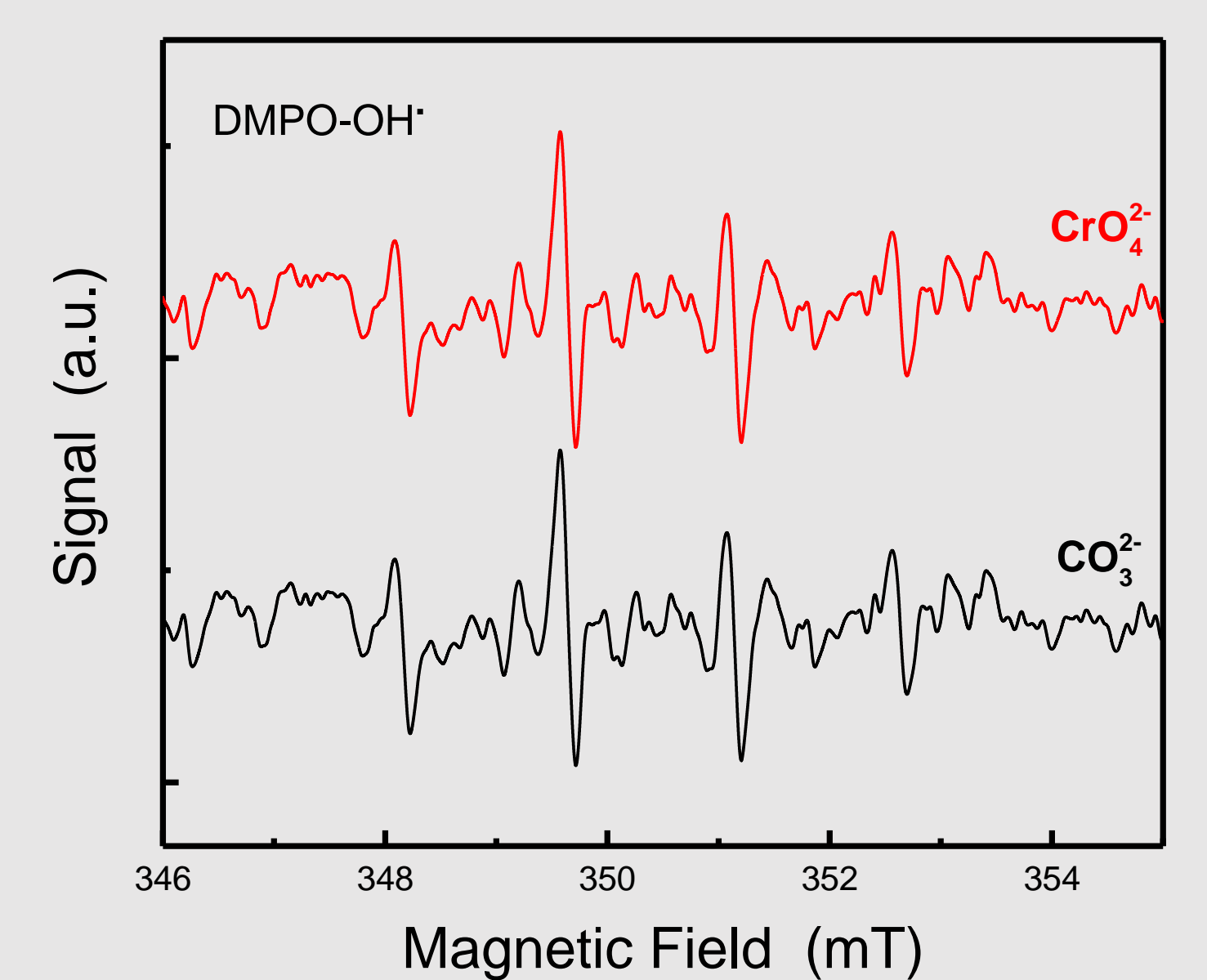

$\mathrm{LDH}-\mathrm{CO}_{3}$ and $\mathrm{LDH}-\mathrm{CrO}_{4}$ samples produce similar amount of $\bullet \mathrm{OH}$ radical. However, $\mathrm{LDH}-\mathrm{CrO}_{4}$ show an intense signal of $\bullet \mathrm{O}_{2}$ - radical.

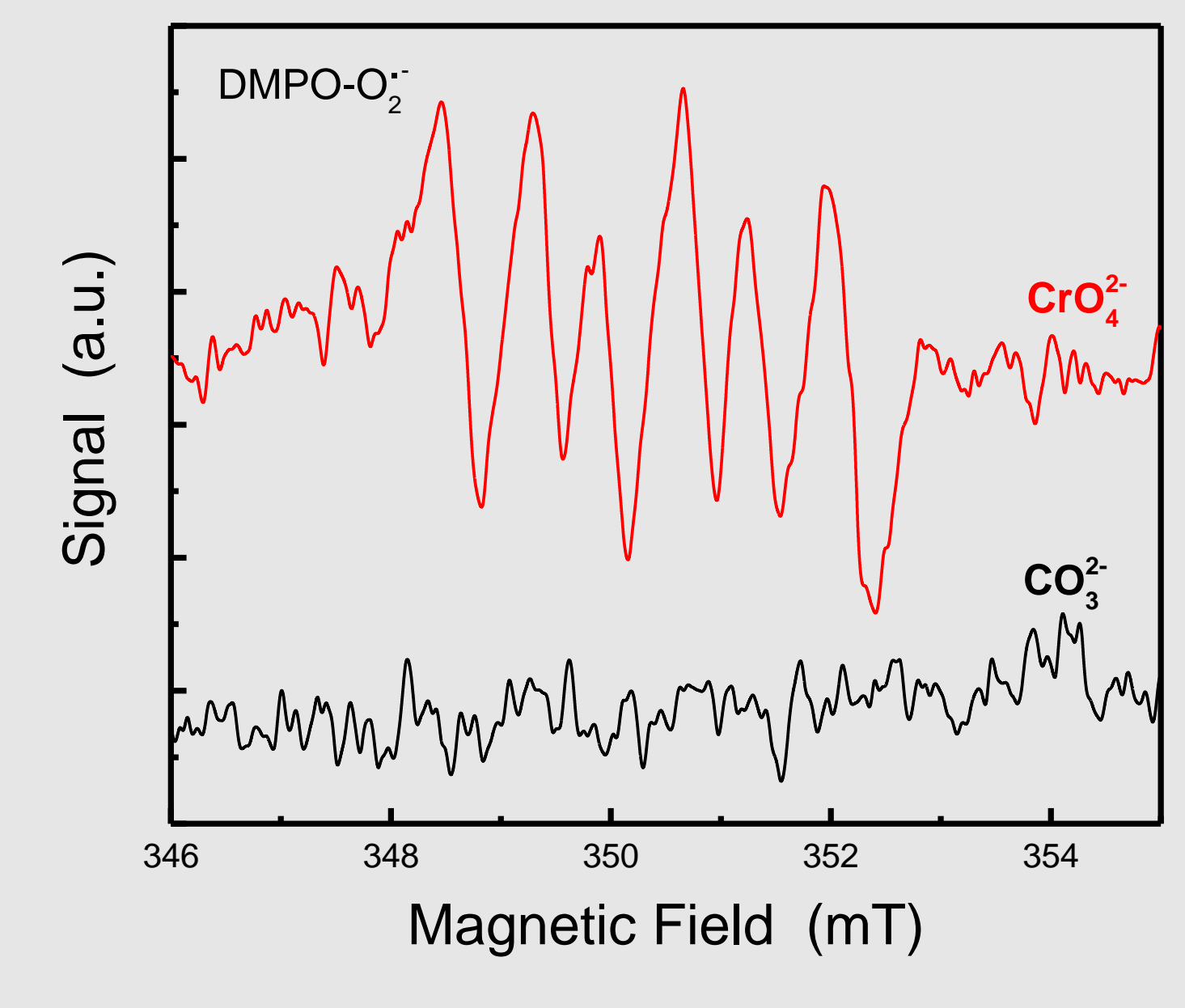

